\title{
Predictive value of uterine artery: peak systolic velocity on the day of trigger for clinical pregnancy rate in infertile women
}

\author{
Karishma Makhija*, Deepti Shrivasatava, M. Tiwari
}

Department of Obstetrics and Gynecology, Jawharlal Nehru Medical College, Wardha, Maharashtra, India

Received: 09 November 2018

Accepted: 13 December 2018

\section{*Correspondence:}

Dr. Karishma Makhija,

E-mail: akmakhija11@gmail.com

Copyright: (C) the author(s), publisher and licensee Medip Academy. This is an open-access article distributed under the terms of the Creative Commons Attribution Non-Commercial License, which permits unrestricted non-commercial use, distribution, and reproduction in any medium, provided the original work is properly cited.

\begin{abstract}
Background: The purpose of the study is to evaluate the role of uterine artery blood flow parameter measured by uterine artery two-dimensional (2D) power coloured doppler (PCD) ultrasound in predicting fertility outcomes in women undergoing ART treatment.

Methods: It is prospective observational study. Total of 60 patients were included of receiving infertility treatment in the age group20-40 years. 20 patients were selected for timed intercourse, 20 patients were selected for intrauterine insemination , 20 patients were selected for invitro fertilization. Transvaginalsonography will be done on the day of trigger by BHCG, UA PSV were measured, and endometrial blood flow will be assessed. Predictivity of pregnancy rate will be looked after by 3 ways: BHCG values , UPT, Gestational sac on USG.

Results: In TI/IUI/IVF cycles the Doppler parameter PSV of uterine artery $(23.08+/-3.39$ vs $20.37-/+5.43)$ in pregnant vs non-pregnant group did not differ significantly. The mean PSV of UA shows no significant difference women who were became pregnant during treatment and the women who were not became pregnant.

Conclusions: With help of Doppler parameter imaging of women undergoing infertility it was found that UA PSV is non-significant to decide the prediction of pregnancy outcome.
\end{abstract}

Keywords: 2D power colored doppler, Intrauterine insemination, Invitro fertilization, Peak systolic velocity (PSV), Timed intercourse, Uterine artery (UA)

\section{INTRODUCTION}

The World Health Organization (WHO) estimates that approximately $8 \%-10 \%$ of couples experience infertility problem due to various explained and unexplained reasons. In vitro fertilization and embryo transfer (IVFET) is endorsed and is selectively and readily available for the management of infertility. The most exasperating problem with the IVF-ET is implantation failure, which decreases the treatment success rate to $15-45 \% .^{1}$ The pregnancy outcome depends upon diverse aspects related to IVF cycles. $30 \%$ of infertile partners in the world have been diagnosed as unexplained / idiopathic infertility and this is defined as "the lack of an obvious cause for a couple's infertility and the females' inability to get pregnant after at least 12 cycles of unprotected intercourse or after six cycles in women above 35 years of age for whom all the standard evaluations are normal". ${ }^{2}$ A receptive endometrium is necessary for successful implantation Endometrial blood flow reflects the receptivity of endometrium since implantation takes place in endometrium. ${ }^{3}$ Uterine perfusion and its impedance have been found to be an indicator for the likelihood of subsequent implantation. ${ }^{4-6}$ Uterine artery Doppler has been used as marker to predict chances of pregnancy. Impaired perfusion of uterine artery can lead to unsuccessful IVF treatment therefore probably a cause of infertility. ${ }^{7}$ Colour Doppler can be used to asses Uterine artery blood flow velocimetry. The advent of transvaginal ultrasound with $2 \mathrm{D}$ and $3 \mathrm{D}$ power Doppler 
has provided a perfect non-invasive tool to assess endometrial receptivity. Measurement of endometrial blood flow using $2 \mathrm{D}$ power Doppler in ART treatment and their role in predicting outcome has attracted a lot of attention across the world in recent years.

The aim of this study was to evaluate the role of uterine artery blood flow parameter measured by 2D power Doppler ultrasound as the predictive factors for pregnancy during ART treatment.

\section{METHODS}

It was a prospective non-randomized observational study conducted in the Dept of Obstetrics and Gynecology in JNMC Sawangi (Meghe),Wardha from September 2017 to September 2018. A total 60 patients of receiving infertility treatment in the age group 20 to 40 years were included. 20 patients with timed intercourse were selected. 20 patients receiving IUI were selected. 20 patient receiving IVF treatment were selected. Transvaginalsonography will be done on trigger day. Endometrial thickness on trigger day was measured.

\section{Inclusion criteria}

- Women with primary or secondary infertility.

- Patient with unexplained infertility.

- Age<40 years,

- Ovaries with normal morphology i.e. non-polycystic

- Basal FSH level should be less then <10 IU/L on day 2 OF cycle were included in the study.

\section{Exclusion criteria}

- h/o any of uterine surgery

- Any apparent pathology of endometrial

- Systemic diseases like ulcerative colitis, diabetes, Crohn's disease, connective tissue diseases or hypertension

- Women with other endocrinal problem like Thyroid, Prolactin, Adrenal disorders.

Women fulfilling's the inclusion criteria written informed consent was taken. Day 2 FSH/LH/SERUM E2 and $\mathrm{AMH}$ in all women was done. Selected women were undergoing infertility treatment, taking ovulation induction and trigger with timed intercourse, IUI or IVF procedure using a standard ovarian stimulation protocol.

The Transvaginal ultrasound examination performed in lithotomy position after passing urine to empty bladder. Follicular scan was performed on alternate days from day 7 onwards till Dominant Follicular Size Reach 18-20MM. The peak systolic velocity (PSV) of the uterine artery will be measured. using transvaginal colour Doppler measurements on trigger day in selected women. Trigger was given with human chorionic gonadotrophin injection. These women received 10,000 IU hCG as a trigger in single dose.
The primary endpoint of fertility treatment was followed, which was taken as successful pregnancy in terms of value of beta hCG after 1 week of trigger, urine pregnancy test after 2 weeks of expected menses and visible gestational sac on trans vaginalsonography after 12 weeks of last menstrual period. Ongoing pregnancy will be defined as "the presence of fetal cardiac activity at 12 weeks' gestation” was taken as clinical pregnancy.

On the saggital view of uterus, by using colour Doppler uterine artery flow was measured at the level of internal cervical os. The angle between the vessels the Doppler wave was kept close to zero.

The angle of measurement was less then $40^{\circ}$, and in all cases angle correction was performed. PSV was recorded. Indices values for uterine artery vessel was calculated electronically after wave forms in three consecutive cardiac cycles were obtained.

\section{RESULTS}

\section{Comparison of different hormonal levels of the patients of the three types of intervention}

One-way ANOVA showed that there were significant differences in mean Level of Follicle Stimulating Hormone $(\mu / \mathrm{ml})$ at $2^{\text {nd }}$ day, level of Estradiol $(\mathrm{pg} / \mathrm{ml})$ at 2nd day and Level of luteinizing hormone at 2 nd day $(\mu / \mathrm{ml})$ of the patients of the three groups $(p>0.05)$ (Table 1).

\section{Comparison of BHCG of the patients of the three types of intervention}

One-way ANOVA showed that there was no significant difference in BHCG of the patients of the three groups $(\mathrm{p}=0.50)$ (Table 2).

Comparison of PSV trigger [PSV (peak systolic velocity $(\mathrm{cm} / \mathrm{sec})]$ of the pregnant and non-pregnant women

t-test showed that there was no significant difference in the mean Peak systolic velocity of the women who were became pregnant during treatment and the women who were not became pregnant during treatment $(\mathrm{t} 58=1.95$; $\mathrm{p}=0.064)$ (Table 3).

\section{Pregnancy rate and type of intervention of the patients}

Chi-square test showed that there was significant association between status of pregnancy and type of intervention of the patients $(\mathrm{p}<0.001)$.

Proportion of pregnant women was higher for IVF $(47.1 \%)$ higher than that for intrauterine insemination $(29.4 \%)$ and timed intercourse $(23.5 \%) \quad(\mathrm{Z}=2.62$; $\mathrm{p}=0.008)$ (Table 4). 
Table 1: Comparison of different hormonal levels of the patients of the three types of intervention.

\begin{tabular}{|c|c|c|c|c|c|}
\hline Parameters & IVF $(n=20)$ & Intrauterine insemination $(\mathrm{n}=\mathbf{2 0})$ & Timed intercourse $(\mathrm{n}=\mathbf{2 0})$ & $\mathbf{F}_{2,57}$ & p-value \\
\hline \multicolumn{6}{|c|}{ Level of follicle stimulating hormone $(\mu / \mathrm{ml})$ at $2^{\text {nd }}$ day } \\
\hline Mean \pm SD & $4.34 \pm 2.92$ & $3.51 \pm 2.05$ & $3.52 \pm 2.43$ & \multirow{3}{*}{0.742} & \multirow{3}{*}{$0.481 \mathrm{NS}$} \\
\hline Median & 3.88 & 3.35 & 2.91 & & \\
\hline Range & $1.00-9.23$ & $0.96-9.33$ & $0.90-9.80$ & & \\
\hline \multicolumn{6}{|c|}{ Level of estradiol $(\mathrm{pg} / \mathrm{ml})$ at $2^{\text {nd }}$ day } \\
\hline Mean \pm SD & $72.31 \pm 55.28$ & $59.38 \pm 48.57$ & $54.39 \pm 44.24$ & \multirow{3}{*}{0.696} & \multirow{3}{*}{$0.503 \mathrm{NS}$} \\
\hline Median & 45.82 & 44.775 & 39.56 & & \\
\hline Range & $22.65-220.10$ & $16.07-233.00$ & $17.66-193.51$ & & \\
\hline \multicolumn{6}{|c|}{ Level of luteinizing hormone at $2^{\text {nd }}$ day $(\mu / \mathrm{ml})$} \\
\hline Mean \pm sd & $4.18 \pm 2.69$ & $3.85 \pm 2.75$ & $4.34 \pm 2.61$ & \multirow{3}{*}{0.172} & \multirow{3}{*}{$0.842 \mathrm{NS}$} \\
\hline Median & 3.31 & 3.46 & 3.80 & & \\
\hline Range & $0.52-10.86$ & $1.00-11.39$ & $1.40-11.80$ & & \\
\hline
\end{tabular}

Table 2: Comparison of BHCG of the patients of the three types of intervention.

\begin{tabular}{|l|l|l|l|l|l|}
\hline BHCG & IVF $(\mathbf{n = 2 0})$ & Intrauterine insemination $(\mathrm{n}=20)$ & Timed Intercourse $(\mathrm{n}=20)$ & $\mathrm{F}_{2,57}$ & $\mathrm{p}$-value \\
\hline Mean \pm SD & $416.55 \pm 544.39$ & $436.35 \pm 538.09$ & $605.80 \pm 582.29$ & \multirow{2}{*}{0.702} & $0.50 \mathrm{NS}$ \\
\hline Median & 53.00 & 71.5 & 780.00 & $1-1,490$ & \\
\hline Range & $0-1,466$ & $1-1,420$ & & \\
\hline
\end{tabular}

Table 3: Comparison of PSV trigger [PSV (peak systolic velocity $(\mathrm{cm} / \mathrm{sec})]$ of the pregnant and non-pregnant women.

\begin{tabular}{|l|l|l|l|l|}
\hline Peak systolic velocity $(\mathrm{cm} / \mathrm{sec})$ & Pregnant $(\mathrm{n}=1 \mathbf{8})$ & Non-pregnant $(\mathrm{n}=\mathbf{4 2})$ & t58 & p-value \\
\hline Mean \pm sd & $23.08 \pm 3.39$ & $20.37 \pm 5.43$ & \multirow{2}{*}{1.95} & 0.064 NS \\
\hline Median & 20.75 & 19.95 & $11-32$ & \\
\hline Range & $14-40$ & $11-32$ & & \\
\hline
\end{tabular}

NS- Statistically not significant

Table 4: Pregnancy rate and type of intervention of the patients.

\begin{tabular}{|l|l|l|l|}
\hline Type of intervention & Pregnant $(\mathbf{n = 1 8})$ & Non-pregnant $(\mathbf{n = 4 2})$ & TOTAL \\
\hline IVF & 8 & 12 & 20 \\
\hline Row \% & 40.0 & 60.0 & 100.0 \\
\hline Col \% & 47.1 & 28.6 & 33.3 \\
\hline Intrauterine Insemination & 5 & 15 & 20 \\
\hline Row \% & 25.0 & 75.0 & 100.0 \\
\hline Col \% & 29.4 & 35.7 & 33.3 \\
\hline Timed Intercourse & 4 & 15 & 20 \\
\hline Row \% & 20.0 & 80.0 & 100.0 \\
\hline Col \% & 23.5 & 35.7 & 33.4 \\
\hline TOTAL & 17 & 42 & 60 \\
\hline Row \% & 30.0 & 70.0 & 100.0 \\
\hline Col \% & 100.0 & 100.0 & 100.0 \\
\hline
\end{tabular}

\section{DISCUSSION}

In this study, authors determined the value of Doppler ultrasonographic indice PSV of uterine and arcuate arteries for predicting IVF outcome among infertile women in Wardha. In this study hormonal levels and BhCG did not differ significantly in different type of intervention of the patients. The pregnancy rate in IVF-
ET cycles depends on a wide array of factors associated with different aspects of assisted reproduction. Uterine blood flow parameters might be one of these factors affecting implantation. Steer et al suggested that poor uterine perfusion determined by uterine artery color doppler could be a cause for implantation failure among unsuccessful IVF patients. ${ }^{5}$ This assessment prompted the present study where the quantitative measurement of PSV 
of uterine artery was conducted and the correlation between the same and the pregnancy rates was sought in ART cycles Puerto et al in Spain have indicated that ultrasonographic markers as the predictors of implantation after IVF have a limited value when measured during embryo transfer. ${ }^{8}$

NG et al. evaluate the role of endometrial blood flows in the prediction of pregnancy during IVF treatment. They concluded that endometrial blood flows measured by three-dimensional power Doppler ultrasound were not good predictors of pregnancy during IVF treatment, if they were measured once. ${ }^{9}$

In the study of Sudha Prasad et al, It was found that in pregnant and non-pregnant group (group A 26.17 \pm 8.94 group B 24.63 \pm 1.126 ) There was no significant changes between the mean PSV of uterine artery. ${ }^{10}$ In the study of Guzel AII et al reported that in non-pregnant and Pregnant group Doppler velocimetry did not differ significantly. ${ }^{11}$ In similar study, Ivanovski $M$ in uterine artery and arcuate artery, in the pregnant group mean Peak systolic velocity were higher than in the non-PN regnant group; but difference noted was not significant. ${ }^{12}$ In study of Ursula Zollner concluded that in non-pregnant and pregnant group the uterine artery peak systolic velocity (60 vs. 63) did not differ significantly. ${ }^{13}$ In the study of Engmann LI et al reported that not differs significantly in the mean PSV values (uterine artery) between conception cycles and nonconception cycles. ${ }^{14}$

In the study of Atoosa Adibi concluded that in women with successful IVF cycle ,Mean PSV(uterine artery) was significantly higher than in those with unsuccessful IVF outcome $(\mathrm{P}<0.05) .{ }^{15}$ In another contrast study NG et al concluded that during IVF treatment endometrial blood flow velocimetry measured by Doppler ultrasound were not actually good predictors for prediction of conception, when measured only single time. ${ }^{9}$ In addition, further investigations are required on the associations of different uterine factors having higher impacts on successful pregnancy outcome in women undergoing IVF cycles.

Good endometrium triple line pattern, oocyte quality, and numerous autocrine, paracrine and endocrine factors inexorably influence the embryo endometrium cross talk that assessment of low or high uterine artery perfusion alone fails to correlate significantly with implantation rates. Thus, uterine artery $2 \mathrm{D}-\mathrm{PCD}$ indices may be used with some of these factors to form a predictive algorithm for IVF pregnancy rates but independently is not a predictor for IVF implantation or pregnancy rates.

It seems that the controversial results which have reported in different studies are due to the differences in patients' characteristics, the protocol of ovarian stimulation, the day of ultrasound evaluation and the methods of ultrasonographic assessments.
The limitation of this study was the small sample size of the studied population and for obtaining more conclusive results especially for determining the diagnostic value of studied ultrasonographic indices further studies with larger sample size is recommended.

Funding: No funding sources

Conflict of interest: None declared

Ethical approval: The study was approved by the Institutional Ethics Committee

\section{REFERENCES}

1. National center for chronic disease prevention and health promotion Assisted reproductive technology. Atlanta (GA): US Dept of Health and Human Services; 2014:82.

2. Gelbaya TA, Potdar N, Jeve YB, Nardo LG. Definition and epidemiology of unexplained infertility. Obstet Gynecol Surv. 2014;69(2):10915.

3. Mishra VV, Agarwal R, Sharma U, Aggarwal R, Choudhary S, Bandwal P. Endometrial and subendometrial vascularity by three-dimensional (3D) power Doppler and its correlation with pregnancy outcome in frozen embryo transfer (FET) cycles. J Obstet Gynecol India. 2016;66(1):521-7.

4. Salle B, Bied-Damon V, Benchaib M, Desperes S, Gaucherand P, Rudigoz RC. Preliminary report of an ultrasonography and colour Doppler uterine score to predict uterine receptivity in an in-vitro fertilization programme. Hum Reprod. 1998;13(6):1669-73.

5. Steer CV, Tan SL, Dillon D, Mason BA, Campbell S. Vaginal color Doppler assessment of uterine artery impedance correlates with immunohistochemical markers of endometrial receptivity required for the implantation of an embryo. Fertil Steril. 1995;63 (1):101-8.

6. Cacciatore B, Simberg N, Fusaro P, Tiitinen A. Transvaginal Doppler study of uterine artery blood flow in in vitro fertilization-embryo transfer cycles. Fertil Steril. 1996;66(1):130-4.

7. Goswamy RK, Steptoe PC. Doppler ultrasound studies of the uterine artery in spontaneous ovarian cycles. Hum Reprod. 1988;3(6):721-6.

8. Puerto B, Creus M, Carmona F, Civico S, Vanrell JA, Balasch J. Ultrasonography as a predictor of embryo implantation after in vitro fertilization: A controlled study. Fertil Steril. 2003;79(4):1015-22.

9. $\mathrm{Ng} \mathrm{EH}$, Chan CC, Tang OS, Yeung WS, Ho PC. The role of endometrial blood flow measured by threedimensional power Doppler ultrasound in the prediction of pregnancy during in vitro fertilization treatment. Eur J Obstet Gynecol Reprod Biol. 2007;135(1):8-16.

10. Prasad S, Goyal R, Kumar Y, Nayar P, Hajela S, Kumaran A, Vairagi R, Chauhan S. The relationship between uterine artery two-dimensional color doppler measurement and pregnancy outcome: a prospective observational study. J Reproduct Infertil. 2017;18(2):251. 
11. Guzel AI, Erk1lınc S, Ozer I, Tokmak A, Sahin AK, Ugur M. Are uterine and ovarian artery Doppler velocimetry values good pregnancy predictors in clomiphene citrate cycles? Int J Fertil Steril. 2015;9(1):41.

12. Ivanovski M, Damcevski N, Radevska B, Doicev G. Assessment of uterine artery and arcuate artery blood flow by transvaginal color Doppler ultrasound on the day of human chorionic gonadotropin administration as predictors of pregnancy in an in vitro fertilization program. Akusherstvo I Ginekologiia. 2012;51(2):55-60.

13. Zollner U, Specketer MT, Zollner KP, Dietl J. Uterine artery blood flow in the periimplantation period in embryo transfer cycles. Asian Pacific $\mathbf{J}$ Reproduct. 2012;1(3):177-82.

14. Engmann L, Sladkevicius P, Agrawal R, Bekir J, Campbell S, Tan SL. The pattern of changes in ovarian stromal and uterine artery blood flow velocities during in vitro fertilization treatment and its relationship with outcome of the cycle. Ultrasound in Obstetrics and Gynecology: J Int Soc Ultras Obstet Gynecol. 1999;13(1):26-33.

15. Adibi A, Khadem M, Mardanian F, Hovsepian S. Uterine and arcuate arteries blood flow for predicting of ongoing pregnancy in in vitro fertilization. Journal of research in medical sciences: Off $\mathrm{J}$ Isfahan University of Med Sci. 2015;20(9):879.

Cite this article as: Makhija K, Shrivasatava D, Tiwari M. Predictive value of uterine artery: peak systolic velocity on the day of trigger for clinical pregnancy rate in infertile women. Int J Reprod Contracept Obstet Gynecol 2019;8:677-81. 